Available online at http://www.ifg-dg.org

Int. J. Biol. Chem. Sci. 10(3): 1370-1381, June 2016

ISSN 1997-342X (Online), ISSN 1991-8631 (Print)

$\overline{\text { International Journal }}$

of Biological and

Chemical Sciences

$\mathrm{O}_{2}$

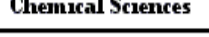

Review Paper http://ajol.info/index.php/ijbcs http://indexmedicus.afro.who.int

\title{
Environmental tobacco smoke exposure and its health impacts: a review
}

\author{
Alemayehu GASHAW $^{1 *}$, Abile TESHITA ${ }^{2}$ and Tewodros GETACHEW ${ }^{1}$ \\ ${ }^{1}$ Department of Chemistry, Faculty of Natural and Computational Sciences, \\ Bule Hora University, Bule Hora, Ethiopia. \\ ${ }^{2}$ Department of Biology, Faculty of Natural and Computational Sciences, \\ Bule Hora University, Bule Hora, Ethiopia. \\ *Corresponding author; E-mail: alexgashaw@gmail.com, \\ Tel: +251910788274 , Fax: +251464430355
}

\begin{abstract}
Worldwide tobacco smoking kills nearly 6 million people each year, including more than 600,000 non-smokers who die from smoke exposure. Tobacco smoke is a toxic and carcinogenic mixture of more than 5,000 chemicals. Environmental Tobacco Smoke (ETS), or secondhand smoke, is the combination of side stream smoke, the smoke given off by a burning tobacco product and mainstream smoke, the smoke exhaled by smokers. Exposure to Environmental Tobacco Smoke is detrimental to health which may pose a health risks to nonsmokers. Epidemiological data suggest that exposure to ETS may increase the risk of developing lung cancer, stroke, heart disease, cardiovascular disease, intrauterine growth retardation, predisposition to chronic lung disease, sudden infant death syndrome and is a risk factor for childhood asthma. The human populations most at risk from ETS exposure appear to be neonates, young children, and possibly the fetus while in uterus. The effects of ETS on human health are well-known, passive smoking is harmful to those who breathe the toxins and it is a serious problem for public health. Therefore, the decrease in smoking prevalence could provide substantial health gains in humans. This article reviews information on environmental tobacco smoke (ETS) particles that are of potential interest to scientists and professionals involved in exposure or risk assessment, epidemiology, or tobacco policy and to compile effective ways of reducing exposure in order to contribute to the wellbeing of human.
\end{abstract}

(c) 2016 International Formulae Group. All rights reserved.

Keywords: Environmental Tobacco Smoke, side stream smoke, main Stream smoke, tobacco.

\section{INTRODUCTION}

Tobacco smoke is a complex, dynamic and reactive mixture containing an estimated 5,000 chemicals (Talhout et al.,
2011; Nikolić et al., 2012). This toxic and carcinogenic mixture is probably the most significant source of toxic chemical exposure and chemically mediated disease in humans. 
In the recent years, the exposure to ETS has been an important public health hazard. Several reports have also emphasized that exposure to ETS can cause lung cancer in people who have never smoked (Pandey and $\mathrm{Kim}, 2010)$. It is a major risk factor for respiratory disease in children and the most important source of ETS exposure is within the home (Horak et al., 2007).

ETS composed of side stream smoke (SS), the smoke emitted from the smoldering tobacco between puffs, and mainstream smoke (MS), the smoke from the smoker (Jenkins et al., 2000; WHO, 2000). The side stream smoke is shown to contain about the same hazardous substances as mainstream smoke. Quantitatively, however, side stream smoke contains much more of the different chemical constituents, varying from double to the hundred folded amounts for the different chemical constituents. This is due to the lower burning temperature between the "puffs". More than $75 \%$ of the nicotine emitted from a cigarette is emitted into the air as side stream smoke (Pandey and Kim, 2010).

Worldwide, tobacco smoking kills nearly 6 million people each year, including more than 600,000 non-smokers who die from smoke exposure. The World Health Organization estimates that approximately half of the children in the world are exposed to ETS mostly in their homes (Tsai et al., 2010) and by 2030 tobacco will kill more than 8 million people worldwide each year (Talhout et al., 2011; Giraldi et al., 2013). For instance, in Taiwan, school children are not typically exposed in public due to the legislative ban on public smoking and regular health promotion campaigns; home exposure is likely the dominant source of ETS. It was reported that approximately $60 \%$ Taiwanese children under the age of 17 were exposed to household ETS, and therefore an estimated 3.3 million children were at risk for adverse health effects from this exposure (Tsai et al., 2010).

ETS exposure during pregnancy and the first years of life has been consistently found to have an impact on the respiratory system including symptoms such as wheezing, cough, bronchitis, otitis media and asthma, but also on intrauterine growth, sudden infant death, behavior and cognitive functioning (Horak et al., 2007). Exposure to the mother's active smoking or maternal smoking affects the lungs of the fetus as it develops in uterus. Another explanation is that mothers are physically closer to their children while providing for their care during postnatal, thus exposing the children to a larger dose of ETS (Witschi et al., 1997). Prenatal and postnatal ETS exposure constitutes a determinant factor in respiratory morbidity in children and early lung function reduction. Various studies have demonstrated that ETS exposure adversely affects children's respiratory health by diminishing lung growth and increasing the risk of infections and respiratory symptoms, including wheezing and asthma exacerbation. Children are exposed to tobacco smoke not only in their homes, but also in schools, restaurants, child care settings, cars, buses and other public places. In Ethiopia, parental smoking at home is likely the commonest source of children's exposure to ETS (Horak et al., 2007).

In 2004, an estimated 600,000 individuals died of exposure to secondhand smoke, of which 53,000 were in Africa. These deaths were mostly caused by ischemic heart disease for adults and lower respiratory infections for children (WHO, 2011).

National smoking prevalence among men in sub-Sahara Africa varies from $20 \%$ to $60 \%$ and the annual cigarette consumption rates are on the rise for both men and women. Among sub-Saharan African youth, rates of smoking range from $1.4 \%$ in Zimbabwe and $1.5 \%$ in Nigeria to $34.4 \%$ in Cape Town, South Africa, which is a cause for concern. In Kenya, $7.2 \%$ of school-going adolescents smoke cigarettes while $8.5 \%$ use other forms of tobacco products. In Ethiopia, in 1983 life time prevalence rate of cigarette smoking among college students was reported to be $31.9 \%$ (Ahmed et al., 1984) and the prevalence of smoking among young Ethiopian (15-25 years of age) living in Addis-Ababa was $11.8 \%$ for males and $1.1 \%$ for females in 1995 (Rudatsikira et al., 2007). 
The most common tobacco smoke related causes of death, are cardiovascular disease, chronic obstructive pulmonary disease, and various types of cancer, in particular lung cancer. In addition, smoking tobacco is a major cause of illness and premature death (Pandey and Kim, 2010). Chronic obstructive pulmonary disease (COPD) is a leading cause of chronic morbidity and mortality. According to the Global Burden of Disease Study (Yildiz et al., 2010), COPD was the $6^{\text {th }}$ leading cause of death worldwide in 1990, and it is predicted to become the $3^{\text {rd }}$ most common cause of death and the $4^{\text {th }}$ most important disabilityproducing illness by 2020 (Yildiz et al., 2010).

According to WHO, more than $30 \%$ of world's adult population is becoming consumers of tobacco and therefore it warns that a billion people will die of adverse health effects of tobacco epidemic within the $21^{\text {st }}$ century unless effective measures are undertaken. The public health challenge of tobacco is unique in that tobacco producers undermine public health efforts because they gain unbelievably huge wealth, and power which enables them to endure all sorts of antitobacco policies, and campaigns (Gedefaw et al., 3013). Therefore, obviously, there is a need for regulation of this addictive and harmful product as the most other addictive and/or hazardous products to which the population is exposed. So, it is important to understand the mechanisms through which ETS influences respiratory diseases in childhood to more effectively evaluate and implement interventions to reduce this burden. This review will focus primarily on impact of ETS on human health.

\section{TOBACCO SMOKE}

Tobacco smoke contains thousands of chemicals, many of which are poisonous. The following components of tobacco smoke contribute to disease:

- Nicotine: an addictive drug found in tobacco smoke which causes blood vessels to contract and hence reducing blood flow. Therefore, nicotine increases blood pressure, which makes the heart work harder and also affects brain and muscle activity.

- Carbon monoxide: decreases oxygen intake which in turn reduces the amount of oxygen delivered to the heart by taking the place of oxygen in the blood and thereby makes the heart beat faster (Stefanadis, 2008).

- Tar: coats the lungs like soot in a chimney making it harder to breath. Tar in tobacco contains dozens of chemicals that cause cancer. Of the 4,000 chemicals in tobacco smoke, 50 are associated with causing cancer and promoting tumor growth.

\section{COMPONENTS OF ETS}

Humans may be exposed to a variety of chemical hazards. Tobacco smoking constitutes a significant source of indoor air pollution. Carbonyl compounds, including formaldehyde, have been shown to be major air pollutants. A large number of chemical compounds present in the mainstream and side stream smokes are carcinogenic and also cause long-term toxic effects. Its composition depends on the content of compounds present in the tobacco plant and the various ingredients added to tobacco during the manufacturing process (Demkowska et al. 2010).

Emissions contain both particulate and vapour contaminants. When a cigarette is smoked, roughly half of the smoke generated is SS and the other half MS. Side stream smoke and mainstream smoke are complex mixtures of over 4000 compounds (Table 1) (Matt et al., 2004). These include more than 40 known or suspected human carcinogens and a number of irritants, such as ammonia, nitrogen oxides, etc. are found in tobacco which are shown in Table 2 (WHO, 2000).

\section{ENVIRONMENTAL TOBACCO SMOKE EXPOSURE AND ITS HEALTH EFFECTS}

Exposure is defined as the contact of pollutant with a susceptible surface of the human body. For environmental tobacco smoke, this means contact with the eyes, the epithelium of the nose, mouth and throat, and 
the lining of the airways and alveoli (Jaakkola and Jaakkola, 1997). The smoke accumulates in enclosed spaces and the concentration varies with the number of smokers, with the type of smoking, and with the characteristics of the room, especially the ventilation (Trédaniel et al., 1994). ETS involves inhaling carcinogens and other toxic components, and scientific evidence has unequivocally established that exposure to ETS causes death, disease, and disability in children and adults who do not smoke (Phillips et al., 1994). People may be exposed to environmental tobacco smoke in homes, cars, workplaces (Phillips et al., 1994), and public places, such as bars, restaurants, and recreational settings. In addition, there is another type of smoke which until now has not been considered: the so-called third hand smoke (Figure 1), that comes from the rests of active smoking nicotine (mainstream smoke) that is laid down on the surfaces of indoor environments (cars, clothes, curtains, wallpaper, etc.) and reacts with environmental nitrous acid $\left(\mathrm{HNO}_{2}\right)$ making carcinogenic tobacco-specific nitrosamines (TSNAs). One of the most alarming characteristics of TSNAs is their longevity: they are among the most broadly acting and potent carcinogens present in burned tobacco and tobacco smoke.

According to the Environment Protection Agency, tobacco smoke is classified as group A carcinogen since it has been proved that about 60 components of tobacco smoke have carcinogenic characteristics. Cigarette smoke irritates especially the mucous membranes of the eye, nose, and upper respiratory organs causing inflammation of the sinuses, throat, vocal cords, bronchi, and contributes to the development of emphysema and lung cancer (Jaakkola and Jaakkola, 2002; Goniewicz et al., 2009). Because of the long-term swelling and changes in the mucosa of the nose, the sense of smell can gradually weaken due to the damage of the olfactory nerve. Harmful ingredients of tobacco smoke disrupt the normal function of bronchial epithelium and stimulate the secretion of bronchial mucus (Houtmeyers et al., 1999).
Exposure to tobacco smoke leads to more frequent use of health care, absence from work, and in most cases hospitalization for respiratory diseases. The female population is a special category that needs attention because exposure to tobacco smoke can also seriously affect fertility and may lead to complications in pregnancy and childbirth. Furthermore, prenatal exposure to cigarette smoke affects health of the newborn infant and his/her subsequent school performance. Some studies demonstrated that women married to smokers are at higher risk of lung cancer, ovarian, and endometrial cancer (Badran et al., 2009). Figure 2 shows all of the systems in the body that tobacco smoke affects, both to the smoker and to someone who ingests secondhand smoke.

\section{SERIOUS DISEASES CAUSED BY PASSIVE SMOKING}

ETS exposure during pregnancy and the first years of life has been consistently found to have an impact on the respiratory system including symptoms such as wheezing, cough, bronchitis, RSV bronchiolitis, otitis media and asthma, but also on intrauterine growth, sudden infant death, behavior and cognitive functioning (Horak, 2007). People who regularly spend time in rooms where others smoke are at increased risk for many diseases and disorders. These also include serious diseases such as cancers, cardiovascular and respiratory diseases which require a lot of treatment and can permanently affect a person's quality of life; they can sometimes be fatal (GBE Kompakt, 2010).

\section{Lung cancer}

Environmental tobacco smoke is a major risk factor for respiratory disease. More than 69 of the 4800 chemical compounds in tobacco smoke cause cancer in animals, including humans. These carcinogenic substances irritate the cells lining the respiratory passages and alter their metabolic balance. Normal cells are transformed into cancer cells, which may multiply rapidly and invade surrounding tissues (Solomon et al., 2011). The evidence on ETS and lung cancer 
has been assessed by many health organizations, all of which concluded that exposure to ETS increases the risk of lung cancer (Environmental Tobacco Smoke, 2000). According to Postlethwait and Hopson (2006) tobacco smoke has been found to be the cause of more than 85 percent of all lung cancers. Thousands of non-smokers die of lung cancer each year as a result of breathing secondhand tobacco smoke. There is no safe level of tobacco smoke. Well-known carcinogens include the chemicals in tobacco smoke, asbestos, and ionizing radiation, such as $\mathrm{X}$ rays or Ultraviolet light from the sun. Evidence also shows that the risk of developing lung cancer is increased by up to 30 percent in nonsmokers who live with an individual who smokes in the house, as compared to non-smokers who are not regularly exposed to secondhand smoke. According to the Centers for Disease Control, in the United States of America, the single most preventable cause of disease, disability, and death is tobacco use. Cigarette smoking kills more people than alcohol, car accidents, suicide, AIDS, homicide, and illegal drugs combined. More than 443,000 people die prematurely each year from smoking or exposure to second-hand smoke. Tobacco smoke is by far the most important risk factor for lung cancer, the most common lethal cancer worldwide (Solomon et al., 2011).

\section{Developmental and pregnancy problems}

A woman who actively smokes during pregnancy substantially increases her risk of delivering a low birth-weight infant. Women who do not smoke during pregnancy may still be exposed to environmental tobacco smoke (ETS) (De Lorenze et al., 2002).

Maternal cigarette smoking during pregnancy is associated with increased risk of miscarriage, intrauterine growth retardation, preterm delivery, reduced infant weight, and higher infant mortality. Many studies have also suggested that the pregnant woman's exposure to her partner's smoking may contribute to reduced birth weight (Windham, 1999); paternal smoking also increases the risk of infant respiratory infections and sudden infant death syndrome, irrespective of the maternal smoking status (Wright et al., 1998; Cook and Strachan, 1999; Goel et al., 2004).

Fetuses, neonates, and young children are most at risk from ETS exposure. ETS exposure may not only harm the respiratory system, but also cause adverse reproductive and prenatal outcomes including spontaneous abortion, decreased birth weight, preterm delivery, intrauterine growth retardation and sudden infant death syndrome (Su et al., 2007).

\section{Asthma}

Asthma is a common respiratory disease resulting from an interaction between genetic susceptibility for this disease and exposure to various environmental factors. It is a chronic lung disease that inflames and narrows airways and causes symptoms such as wheezing, chest tightness, shortness of breath, and coughing. Tobacco smoking and exposure to ETS are some of the several important variables which are likely to affect the incidence, recognition and clinical presentation of asthma. Environmental tobacco smoke exposure as a risk factor for asthma and respiratory symptoms is now well accepted in children. There are several studies on the effects of parental smoking on childhood asthma (Gupta et al., 2006; Rushton et al., 2003). Adults with asthma can experience a significant decline in lung function when exposed, while new cases of asthma may be induced in children whose parents smoke. Immediate effects of exposure to second hand smoke include eye irritation, headache, cough, sore throat, dizziness and nausea. Short term exposure to tobacco smoke also has a measurable effect on the heart in nonsmokers (Otsuka, 2001).

As study conducted by Quinto et al. (2013), in girls with asthma, 57.6\% experienced ETS exposure, while $43.6 \%$ of girls without asthma had ETS exposure. No difference was seen in the percentage exposed to ETS between boys with asthma $(50.8 \%)$ and without asthma (44.7\%) (Figure 3). 


\section{MINIMIZING EXPOSURE TO ETS}

Although community efforts to increase cessation and reduce initiation of tobacco use will also eventually reduce ETS exposures, additional interventions are necessary to provide immediate protection for non-smokers in workplaces, public areas, and home environments. Here are some ways to minimize your exposure as well as your risk of disease:

$\checkmark$ Adopt a non-smoking policy in your home. Try to quit or cut back on smoking to improve your health and your children

$\checkmark$ Avoid smoking around other people to reduce their exposure to second-hand smoke.

$\checkmark$ Avoid smoking indoors, especially in areas that are not well ventilated, to reduce second-hand and third hand smoke.

$\checkmark$ Avoid areas where you know there is a chance for smoke to irritate your allergies or sensitivities.

$\checkmark$ Help children avoid second-hand smoke of smokers who use tobacco around them. Have them leave the room or play outside while an adult is smoking. Air rooms out after smoking occurs. Keep smokers away from children's sleeping areas.

$\checkmark$ Non-smokers can reduce their exposure to second-hand smoke by avoiding indoor areas where people smoke or by establishing a smoking ban in their homes or workplaces.

$\checkmark$ Parents who smoke should cover their clothes with a clean jacket or smock before picking up or holding a baby.

\section{Conclusion}

Environmental tobacco smoke is the combination of two forms of smoke from burning tobacco products: Side stream smoke (SS) - smoke emitted between the puffs of a burning cigarette, pipe, or cigar and Mainstream smoke (MS) - the smoke exhaled by the smoker. Exposure to environmental tobacco smoke (ETS) is widespread in the world, the most serious exposures occurring at homes, cars, and public places, such as bars, restaurants, and recreational settings and in the workplace. It is known to be a human carcinogen based on sufficient evidence of carcinogenicity from studies in humans. For instance, exposure to environmental tobacco smoke leads to very serious health effects, especially on the respiratory system. The effects of ETS on human health are wellknown, passive smoking is harmful to those who breathe the toxins and it is a serious problem for public health. Therefore, the decrease in smoking prevalence could provide substantial health gains in humans.

Table 1: Examples of Toxic Constituents in Tobacco Smoke (from over 4,000 identified chemicals) (Foulds et al., 2008).

\begin{tabular}{|c|c|c|c|c|}
\hline $\begin{array}{l}\text { Volatile organic } \\
\text { substances }\end{array}$ & $\begin{array}{c}\text { Polycyclic } \\
\text { aromatic } \\
\text { hydrocarbons }\end{array}$ & Gaseous substances & Nitrosamines & Metals \\
\hline 1,3-butadiene & Benzo(a)pyrene & Ammonia & NNN & Lead \\
\hline Benzene & Pyrene & Hydrogen cyanide & NAB & Cadmium \\
\hline Toluene & Benz(a)anthracene & $\begin{array}{l}\text { Carbon monoxide } \\
\text { Nitrogen Oxides }\end{array}$ & $\begin{array}{c}\text { NNK } \\
\mathrm{N}- \\
\text { Nitrosodimethyl } \\
\text { amine }\end{array}$ & Arsenic \\
\hline Aromatic amine & & Carbonyls & \multicolumn{2}{|c|}{ Aza-arenes } \\
\hline 4-aminobiphenyl & $\begin{array}{c}1- \\
\text { aminonaphthalene }\end{array}$ & $\begin{array}{l}\text { Formaldehyde, } \\
\text { acetaldehyde and } \\
\text { acrolein }\end{array}$ & Quinoline & Dibenz(a.j)acridine \\
\hline
\end{tabular}


Table 2: Emissions of selected tobacco smoke constituents in fresh, undiluted mainstream smoke (MS) and diluted side stream smoke (SS) from unfiltered cigarettes.

\begin{tabular}{|c|c|c|}
\hline Constituent & Emissions in MS & SS/MS ratio \\
\hline \multicolumn{3}{|l|}{ Known Human Carcinogens } \\
\hline - Benzene & $12-48 \mu \mathrm{g}$ & $5-10$ \\
\hline - 2-Naphthylamine & $1.7 \mathrm{ng}$ & 30 \\
\hline - 4-Aminobiphenyl & $4.6 \mathrm{ng}$ & 31 \\
\hline - Nickel & $20-80 \mathrm{ng}$ & $13-30$ \\
\hline - Polonium-210 & $0.04-0.1 \mathrm{pCi}$ & $1-4$ \\
\hline \multicolumn{3}{|l|}{ Probable Human Carcinogens } \\
\hline - Formaldehyde & $70-100 \mu \mathrm{g}$ & $0.1-50$ \\
\hline - Hydrazine & $32 \mathrm{ng}$ & 3 \\
\hline - N-Nitrosodimethylamine & $10-40 \mathrm{ng}$ & $20-100$ \\
\hline - N-Nitrosodiethylamine & ND-25 ng & $<40$ \\
\hline - N-Nitrosopyrrolidine & $6-30 \mathrm{ng}$ & $6-30$ \\
\hline - 1,3-Butadiene & $69.2 \mu \mathrm{g}$ & $3-6$ \\
\hline - Aniline & $360 \mathrm{ng}$ & 30 \\
\hline - Benzo[a]pyrene & $20-40 \mathrm{ng}$ & $2.5-3.5$ \\
\hline - N-Nitrosodiethanolamine & $20-70$ & 1.2 \\
\hline - Cadmium & $110 \mathrm{ng}$ & 7.2 \\
\hline \multicolumn{3}{|l|}{ Toxic Substances } \\
\hline - Carbon Monoxide & $10-23 \mathrm{mg}$ & $2.5-4.7$ \\
\hline - Acrolein & $60-100 \mu \mathrm{g}$ & $8-15$ \\
\hline - Ammonia & $50-130 \mu \mathrm{g}$ & $3.7-5.1$ \\
\hline - Nitrogen Oxides & $100-600 \mu \mathrm{g}$ & $4-10$ \\
\hline
\end{tabular}

Table 3: Variety of illnesses in both adults and children due to ETS.

\begin{tabular}{ll}
\hline Adults & Children \\
\hline Lung cancer & Asthma \\
Heart disease & Bronchitis \\
Increased stroke risk & Cot death \\
Nasal cancer & Low birth weight \\
& Middle ear infection \\
& Pneumonia \\
\hline
\end{tabular}

Smoke lines (2000) an occasional information sheet for community opinion leaders. 


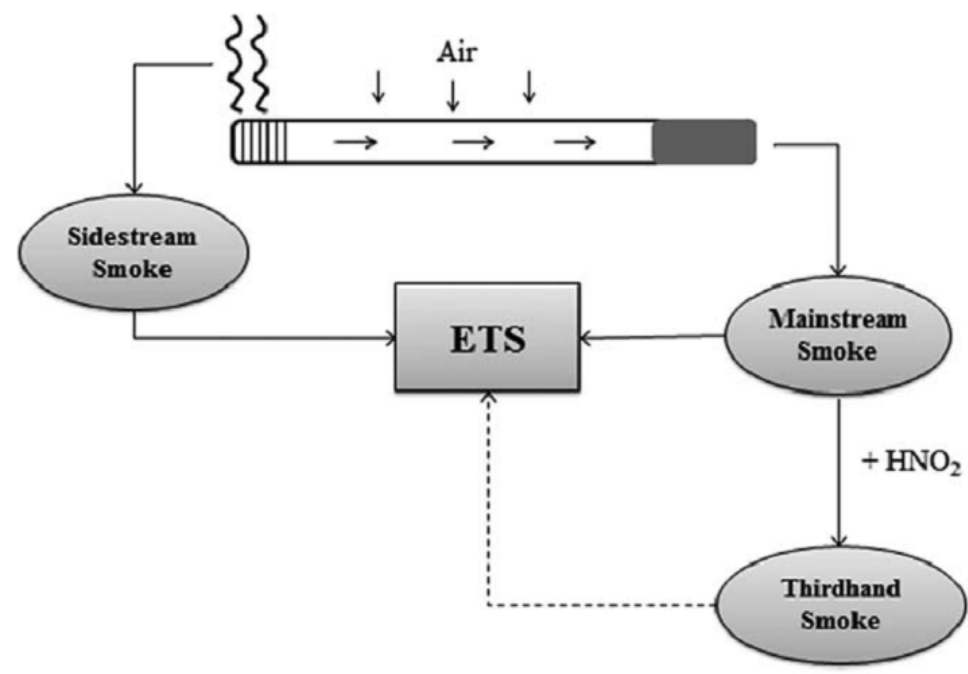

Figure 1: Mechanism of ETS formation. Side stream and mainstream smoke originate from cigarette; third hand smoke is the reaction of mainstream smoke and the environmental nitrous acid $\left(\mathrm{HNO}_{2}\right)$ (Giraldi et al., 2013).

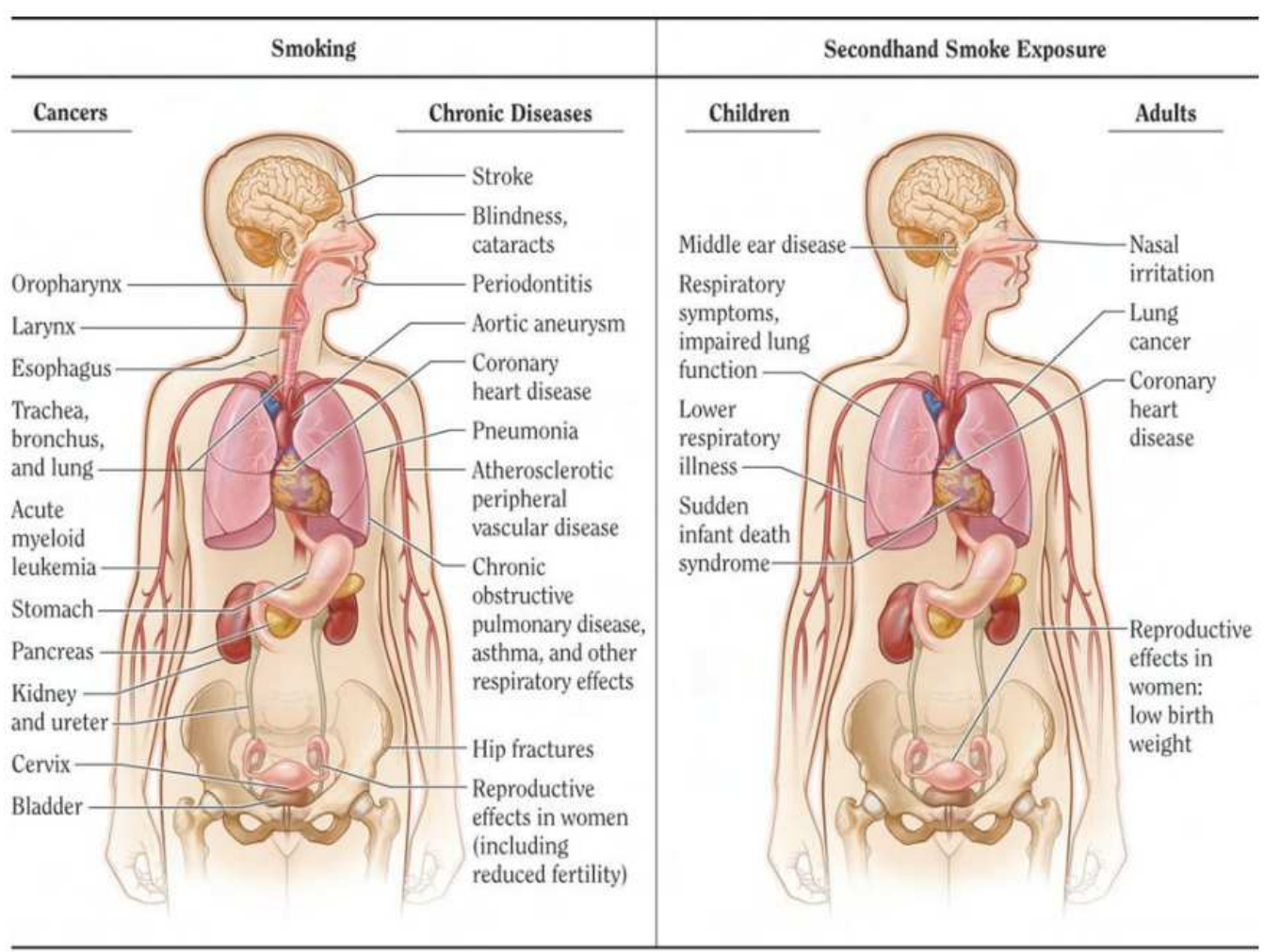

Figure 2: The health consequences causally linked to smoking and exposure to second-hand smoke. (Adapted from U.S. Department of Health and Human Services, 2010). 


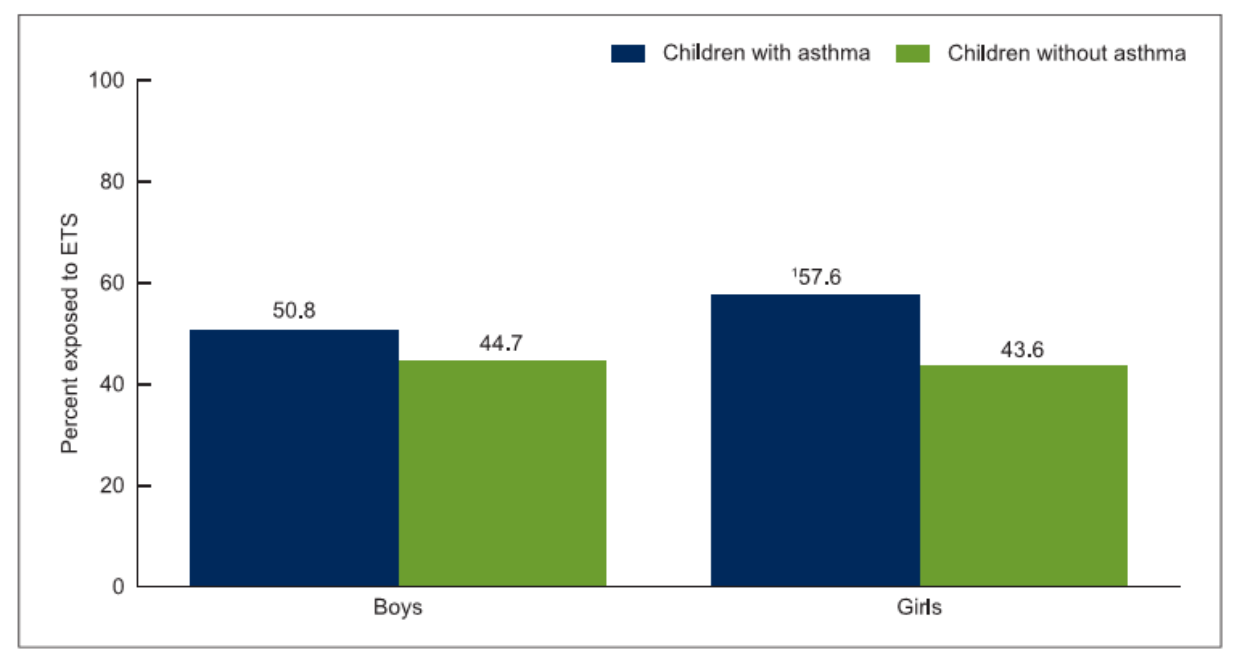

Figure 3: Percentage of children aged 3-19 years exposed to ETS by asthma status and sex.

\section{COMPETING INTERESTS}

The authors declare that they have no competing interests.

\section{AUTHORS' CONTRIBUTIONS}

Each author of this review paper contributed a lot of ideas during the writing this paper. All authors read and approved the manuscript.

\section{ACKNOWLEDGEMENTS}

The authors are grateful to Genet Abera for her contribution.

\section{REFERENCES}

Ahmed Z, Admassu M, Tadesse M, Laeke N, Olango P, Rassu T, Asfaw T. 1984. Patterns of Cigarette smoking among Ethiopian medical and paramedical students. Ethiopian Medical Journal, 22(4):165-171.

Badran E, Salhab AS, Al-Jaghbir M. 2009. Infant exposure to environmental tobacco smoke: Jordan University hospital-based study. Eastern Mediterranean Health Journal, 15(1): 39-46.
Beasley R, Crane J, Lai CK, Pearce N. 2000. Prevalence and etiology of asthma. $J$ Allergy Clin Immunol, 105: 466-472.

Benowitz NL. 1996. Cotinine as a biomarker of environmental tobacco smoke exposure. Epidemiologic Reviews, 18:188-204.

Boldo E, Medina S, Öberg M, Puklová V, Mekel O, Patja K, Dalbokova D, Krzyzanowski M, Posada M. 2010. Global Health Matters. Public Health Reports, 125: 478-487. http://whqlibdoc.who.int/publications /2007/9789241563413_eng.pdf

Chen C, Lee P, Chou Y, Kuo S, Hsu YH. 2007. Avoidance of Environmental Tobacco Smoke among Pregnant Taiwanese Women: Knowledge, Self-Efficacy, and Behavior. Journal of Women's Health, 16(6): 869-878. doi:10.1089/jwh.2006.0198

Cook GD, Strachan DP. 2003. Background paper: Effects of maternal and paternal smoking on children's respiratory health. International Consultation on Environmental Tobacco Smoke and Child Health. World Health Organization, 1999. 
http://www.who.int/toh/TFI/ consult.htm.

DeLorenze GN, Kaufman MKL, Eskenazi B, Bernert JT. 2002. Exposure to Environmental Tobacco Smoke in Pregnant Women: The Association between Self-Report and Serum Cotinine. Environmental Research Section A, 90: 21-32.

Demkowska I, Polkowska Z, Namieśnik J. 2010. Formaldehyde in Human Saliva as an Indication of Environmental Tobacco Smoke Exposure. Polish J. Environ. Stud., 19(3): 573-577.

Environmental Tobacco Smoke. 2000. Air Quality Guidelines. $2^{\text {nd }}$ edn. WHO Regional Office for Europe: Copenhagen, Denmark.

Foulds J, Delnevo C, Ziedonis DM, Steinberg BM. 2008. Health Effects of Tobacco, Nicotine, and Exposure to Tobacco Smoke Pollution. Handbook of the Medical Consequences of Alcohol and Drug Abuse. The Haworth Press, Inc. 434-445.

GBE Kompakt. 2010. Facts and Trends from Federal Health Reporting. Robert Koch Institute, 1(3);1-6.

Gedefaw M, Eshete A, Aychiluhem M, Azale T. 2013. Water-pipe tobacco epidemic in tobacco naive communities: Experience from Ethiopia. Open Journal of Epidemiology, 3: 184-192. DOI: 10.4236/ojepi.2013.34027

Giraldi G, De Ruggiero FG, Marsella LT, d'Alessandro 2013. Environmental tobacco smoke: health policy and focus on Italian legislation. Clin Ter., 164(5): e429435. DOI: $10.7417 /$ CT.2013.1623

Goel P, Radotra A, Singh I, Aggarwal A, Dua D. 2004. Effects of passive smoking on outcome in pregnancy. J Postgrad Med., 50:12-16.
Goniewicz MŁ, Czogała J, Kośmider L, Koszowski B, Zielińska-Danch W, Sobczak A. 2009. Exposure to carbon monoxide from second-hand tobacco smoke in Polish pubs. Cent Eur J Public Health, 17(4): 220-222.

Goodman J. 1995. Tobacco in History: The Cultures of Dependence. Routledge: London and New York.

Gupta D, Aggarwal AN, Chaudhry K, Chhabra SK, D'Souza GA, Jindal SK, Katiyar SK, Kumar R, Shah B, Vijayan VK. 2006. Household Environmental Tobacco Smoke Exposure, Respiratory Symptoms and Asthma in Non-Smoker Adults: A Multicentric Population Study from India. The Indian Journal of Chest Diseases \& Allied Sciences, 48: 31-36.

Horak E, Morass B, Ulmer H. 2007. Association between environmental tobacco smoke exposure and wheezing disorders in Austrian preschool children. SWISS MED WKLY, 137: 608-613. . WwW.smw.ch

Houtmeyers E, Gosselink R, Gayan-Ramirez G, Decramer M. 1999. Regulation of mucociliary clearance in health and disease. Eur Respir J., 13(5): 11771188 .

IARC. 2004. Tobacco smoke and involuntary smoking. IARC Monogr Eval Carcinog Risks Hum., 83: 1-1438.

Jaakkola MS, Jaakkola JJK. 1997. Assessment of exposure to environmental tobacco smoke. Eur. Respir. J., 10: 23842397. DOI: 10.1183/09031936.97. 10102384

Jaakkola MS, Jaakkola JJ. 2002. Effects of environmental tobacco smoke on the respiratory health of adults. Scand $J$ Work Environ Health, 28(2): 52-70.

Jenkins RA, Guerin MR, Tomkins BA. 2000. The Chemistry of Environmental 
Tobacco Smoke: Composition and Measurement $\left(2^{\text {nd }}\right.$ edn). Lewis Boca Raton: London.

Matt GE, Quintana PJE, Hovell MF, Bernert JT, Song S, Novianti N, Juarez T, Floro J, Gehrman C, Garcia M, Larson S. 2004. Households contaminated by environmental tobacco smoke: sources of infant exposures. Tobacco Control, 13: 2937. DOI: $10.1136 /$ tc. 2003.003889

Nikolić M, Stanković A, Ćirić IM. 2012. Household Environmental Tobacco Smoke Exposure and Respiratory Health in School Age Children. Sci. J. Faculty Med. in Niš, 29(4): 175180. DOI:10.2478/v10283-012-0024-4

Otsuka R. 2001. Acute effects of passive smoking on the coronary circulation in healthy young adults. JAMA, 286: 436-441. DOI:10.1001/jama.286.4.436

Pandey SK, Kim K. 2010. Determination of Hazardous VOCs and Nicotine Released from Mainstream Smoke by the Combination of the SPME and GCMS Methods, Sci. World J., 10: 1318-1329. DOI 10.1100/tsw.2010. 127

Phillips K, Howard D, Browne D. 1994. Assessment of personal exposure to environmental tobacco smoke in British nonsmokers. Environ Int., 20: 693-712. DOI: $10.1177 / 1420326 \times 9800700403$

Postlethwait JH, Hopson JL. 2006. Modern Biology. Holt, Rinehart and Winston. A Harcourt Education Company: USA.

Quinto KB, Kit BK, Lukacs SL, Akinbami LJ. 2013. Environmental Tobacco Smoke Exposure in Children Aged 3-19 Years With and Without Asthma in the United States, 1999-2010, NCHS Data Brief No. 126.
Repace J, Kawachi I, Glantz S. 1999. Fact sheet on secondhand smoke. Presented at the $2^{\text {nd }}$ European Conference on Tobacco or Health, Spain, 23-27.

Rice University. 2013. Anatomy \& Physiology. Open Stax College, Houston: Texas.

Rudatsikira E, Abdo A, Muula AS. 2007. Prevalence and determinants of adolescent tobacco smoking in Addis Ababa, Ethiopia. BMC Public Health, 7(176): 1-6.

Rushton L, Courage C, Green E. 2003. Estimation of the impact on children's health of environmental tobacco smoke in England and Wales. The Journal of the Royal Society for the Promotion of Health, 123: $175-180$.

Solomon EP, Berg LR, Martin DW. 2011. Biology $\left(9^{\text {th }}\right.$ edn). Brooks/Cole, Cengage Learning: USA.

Stefanadis CI. 2008. Exposure to SecondHand Smoke and Cardiovascular Health: Time to Act, Hellenic $J$ Cardiol., 48: 63-64.

Su F, Lee M, HSieh W, Chang P, Leon Guo Y, Hurng B, Lin S, Chen P. 2007. The effect of prenatal and postnatal environmental tobacco smoke exposure on infant health. 26: 472480.

Talhout R, Schulz T, Florek E, Benthem J, Wester P, Opperhuizen A. 2011. Hazardous Compounds in Tobacco Smoke. Inter. J. Environ. Res. Public Health, 8(2): 613-628. DOI: 10.3390/ijerph8020613.

Torell U. 2002. The smoking man. [Den rökandemänniskan] Dissertation. Linköping University. Linköping.

Trédaniel J, Boffetta P, Saracci R, Hirsch A. 1994. Exposure to environmental tobacco smoke and adult non- 
neoplastic respiratory diseases. Eur. Respir. J., 7: 173-185.

Tsai C, Huang J, Hwang B, Lee YL. 2010. Household environmental tobacco smoke andrisks of asthma, wheeze and bronchitic symptoms among children in Taiwan. Respir. Res., 11(11): 1-10.

U.S. Department of Health and Human Services. 2010. How Tobacco Smoke Causes Disease: The Biology and Behavioral Basis for SmokingAttributable Disease: A Report of the Surgeon General.l Atlanta, GA: Centers for Disease Control and Prevention, National Center for Chronic Disease Prevention and Health Promotion, Office on Smoking and Health.

Wen CP, Levy DT, Cheng TY, Hsu CC, Tsai SP. 2005. Smoking behaviour in Taiwan. Tobacco Control, 14: 51-55.

WHO TFI (world Health organization Tobacco Free Initiative). 2011. Global estimate of the burden of Disease from Second-hand Smoke. Geneva, Switzerland: WHO.

WHO. 2000. Environmental Tobacco Smoke, Air Quality Guidelines - Second
Edition, Regional Office for Europe, Copenhagen, Denmark, 1-2.

Windham GC. 2003. Background paper: Prenatal exposure to environmental tobacco smoke and fetal growth. International Consultation on Environmental Tobacco Smoke and Child Health. World Health Organization, 1999. http://www.who.int/toh/TFI/consult.h tm

Witschi H, Joad JP, Pinkerton KE. 1997. The Toxicology of Environmental Tobacco Smoke. Annu. Rev. Pharmacol. Toxicol., 37: 29-52. DOI:

10.1146/annurev.pharmtox.37.1.29.

Wright SP, Mitchell EA, Thompson JM. 1998. Risk factors for preterm birth: a New Zealand study. NZ Medical Journal, 111: 14-16.

Yildiz T, Topçu F, Çelik Y, Akyildiz L, Ateş G, Durak D. 2010. Effect of passive smoking on the development of chronic obstructive pulmonary disease in southeastern Turkey. Turk J Med Sci., 40(3): 349-355. DOI:10.3906/sag-0905-11. 